\title{
Food Intake Adaptation to Dietary Fat Involves PSA-Dependent Rewiring of the Arcuate Melanocortin System in Mice
}

\author{
Alexandre Benani, ${ }^{1}$ Cécile Hryhorczuk, ${ }^{2}$ Alexandra Gouazé, ${ }^{1}$ Xavier Fioramonti, ${ }^{1}$ Xavier Brenachot, ${ }^{1}$ \\ Christophe Guissard, ${ }^{2}$ Alice Krezymon, ${ }^{1}$ Thibaut Duparc, ${ }^{3}$ André Colom, ${ }^{3}$ Emmanuelle Nédélec, ${ }^{1}$ Caroline Rigault, ${ }^{1}$ \\ Aleth Lemoine, ${ }^{1}$ Jean Gascuel, ${ }^{1}$ Rita Gerardy-Schahn, ${ }^{4}$ Philippe Valet, ${ }^{3}$ Claude Knauf, ${ }^{3}$ Anne Lorsignol, ${ }^{2}$ \\ and Luc Pénicaud ${ }^{1}$ \\ ${ }^{1}$ Centre des Sciences du Goût et de l'Alimentation, Unité Mixte de Recherche 6265-CNRS, 1324-INRA, Université de Bourgogne, 21000 Dijon, France, \\ ${ }^{2}$ STROMAlab; Unité Mixte de Recherche CNRS-Université Paul Sabatier 5273, EFS, U1031 INSERM, BP 8422531432 Toulouse Cedex 4, France, ${ }^{3}$ Institut des \\ Maladies Métaboliques et Cardiovasculaires, Unité de Recherche 1048 INSERM, F-31432 Toulouse Cedex 4, France, and ${ }^{4}$ Institute for Cellular Chemistry, \\ Hannover Medical School, 30625 Hannover, Germany
}

Hormones such as leptin and ghrelin can rapidly rewire hypothalamic feeding circuits when injected into rodent brains. These experimental manipulations suggest that the hypothalamus might reorganize continually in adulthood to integrate the metabolic status of the whole body. In this study, we examined whether hypothalamic plasticity occurs in naive animals according to their nutritional conditions. For this purpose, we fed mice with a short-term high-fat diet (HFD) and assessed brain remodeling through its molecular and functional signature. We found that HFD for $3 \mathrm{~d}$ rewired the hypothalamic arcuate nucleus, increasing the anorexigenic tone due to activated pro-opiomelanocortin (POMC) neurons. We identified the polysialic acid molecule (PSA) as a mediator of the diet-induced rewiring of arcuate POMC. Moreover, local pharmacological inhibition and genetic disruption of the PSA signaling limits the behavioral and metabolic adaptation to HFD, as treated mice failed to normalize energy intake and showed increased body weight gain after the HFD challenge. Altogether, these findings reveal the existence of physiological hypothalamic rewiring involved in the homeostatic response to dietary fat. Furthermore, defects in the hypothalamic plasticitydriven adaptive response to HFD are obesogenic and could be involved in the development of metabolic diseases.

\section{Introduction}

Some specific brain areas remain "plastic" in adulthood, meaning that they can undergo functional or morphological remodeling. The hypothalamus, which ensures coordination of both endocrine and autonomic functions, and thus long-term stability of the inner milieu, can also undergo remodeling. A wide range of conditions have been shown to induce hypothalamic plasticity, including external sensory stimulations such as variations in the photoperiod or ambient temperature, and individual physiological fluctuations such as during dehydration, lactation and the ovarian cycle (Oliet, 2002; Prevot, 2002; Ebling and Barrett,

Received Jan. 27, 2012; revised July 4, 2012; accepted July 10, 2012.

Author contributions: A.B., A. Lorsignol, and L.P. designed research;A.B., C.H., A.G., X.F., X.B., C.G., A.K., T.D., A.C., E.N., C.R., and C.K. performed research; A. Lemoine and J.G. contributed unpublished reagents/analytic tools; A.B., X.F., R.G.-S., P.V., C.K., A. Lorsignol, and L.P. analyzed data; A.B., X.F., and L.P. wrote the paper.

This work was funded by CNRS, Institut National de la Recherche Agronomique, Agence Nationale de la Recherche (ANR-05-PNRA-004 to L.P.), the Burgundy county (FABER-2009-9201-AA0036500635 to L.P. and A.B.), the Association Française d'Etudes et de Recherches sur l'Obésité (to A.B.), and the Institut B. Delessert (to A.B.). We thank Jeffrey M. Friedman for providing POMC-GFP mice; Sylvian Bauer, Hervé Guillou, and Anne Taupignon for fruitful discussions; Xavier Blanc for providing the isocaloric control diet; Lionel Bretillon and Stéphane Grégoire for HPLC analysis of fat content of diets; Christine Fourreau, Xavier Sudre, and Anne Lefranc for their technical assistance; and the Toulouse RIO Imaging facility for help with confocal imaging.

Correspondence should be addressed to Luc Pénicaud, CSGA, 9E Boulevard Jeanne d'Arc, 21000 Dijon, France. E-mail: luc.penicaud@u-bourgogne.fr.

DOI:10.1523/JNEUROSCI.0624-12.2012

Copyright $\odot 2012$ the authors $\quad 0270-6474 / 12 / 3211970-10 \$ 15.00 / 0$
2008). In addition, hypothalamic plasticity appears to be a widely conserved process found in frogs, birds, rodents, and primates.

The involvement of hypothalamic plasticity in the control of whole-body energy homeostasis emerged as a new concept in 2004 (Pinto et al., 2004). This process seems to be essential and its impairment could contribute to obesity. In laboratory animals, rapid rewiring of the hypothalamus can be achieved by using various experimental procedures, including fasting and hormone treatments with exogenous hormones such as leptin and ghrelin (Pinto et al., 2004; Sternson et al., 2005; Andrews et al., 2008; Yang et al., 2011). Such manipulations produce marked changes in feeding behavior, which are probably triggered, at least in part, by the stimulated hormone-dependent reorganization of synapses in specific hypothalamic neurons (Pinto et al., 2004; Sternson et al., 2005; Andrews et al., 2008; Yang et al., 2011). Nevertheless, whether hypothalamic plasticity could play a role in the regulation of food intake in naive animals according to changes in their nutritional conditions is still unknown. To address this issue, we explored hypothalamic plasticity in adult mice fed a high-fat diet (HFD) for 1 week.

\section{Materials and Methods}

Animals. Protocols that included the manipulation of animals were reviewed by our local ethics board and were in strict accordance with European Community guidelines (directive 86/906). Experiments were 
Table 1. Characteristics of diets indicating energy composition, centesimal composition, and biochemical analysis of lipid content

\begin{tabular}{lcclrr}
\hline & \multicolumn{2}{l}{$\begin{array}{l}\text { Centesimal } \\
\text { composition (\%) }\end{array}$} & \multicolumn{2}{l}{$\begin{array}{l}\text { Energy } \\
\text { content (\%) }\end{array}$} \\
\cline { 2 - 3 } \cline { 5 - 7 } & STD & HFD & & STD & HFD \\
\hline Crude protein & 16 & 20 & Caloric density (kcal/g) & 2.9 & 4.4 \\
Crude oil & 3.1 & 21.8 & Calories from carbohydrate & 60.9 & 42.5 \\
Crude fiber & 3.9 & 3 & Calories from fat & 22.4 & 42.5 \\
Starch & 45.8 & 28 & Calories from protein & 16.7 & 15 \\
Sugar & 3 & 19 & & & \\
Minerals and vitamins & 5.5 & 8 & & & \\
\hline
\end{tabular}

performed with 2-month-old male C57BL/6JOla mice from Harlan Laboratories. The mice were housed individually, and fed a standard pelletized commercial chow diet (A04; Safe) for 1 week after arrival. After acclimatization, they were fed either the same standard diet (STD) or a customized highly palatable high-fat diet (Safe). The characteristics of the diets are given in Table 1. The change of diet was made at 9:00 A.M. and both the standard and high-fat diet were renewed daily at 9:00 A.M. The mice had ad libitum access to food and water. Food consumption and body weight (BW) were measured daily. For metabolic studies by indirect calorimetry, the mice were housed in individual air-tight cages and gas exchanges were monitored using an air analyzer system (Oxylet; BIOSEB). For tissue collection, the mice were killed between 9:30 A.M. and 12:00 P.M. Some experiments used 8- to 10-week-old male transgenic homozygous knockout PST-1 mice. These mice had been generated by using targeted mutations in the ST8SiaIV gene (Eckhardt et al., 2000).

Bilateral injection into the hypothalamus. The mice were placed in a stereotaxic frame (David Kopf Instruments) under anesthesia with $0.5-2 \%$ isoflurane constant gas inhalation (Forene; Abbott Laboratories). After dermal disinfection with Vetadine solution (Vetoquinol), the skin and cranial muscles were incised and the skull was exposed. A small hole was drilled and a needle was inserted to target each ventromedial hypothalamus nuclei successively using the following coordinates: -1.5 $\mathrm{mm}$ posterior to the bregma, $\pm 0.4 \mathrm{~mm}$ lateral to the sagittal suture, and $-5.6 \mathrm{~mm}$ below the skull surface. Endoneuraminidase N (EndoN; AbCys) or artificial CSF (aCSF; Tocris Bioscience) was injected through a 34 ga blunt needle mounted on a $10 \mu$ l syringe (NanoFil device from WPI) controlled by a micropump (UMP2 from WPI). A volume of $400 \mathrm{nl}$ per side of both solutions was delivered into the brain parenchyma at rate of $100 \mathrm{nl} / \mathrm{min}$. EndoN-treated mice received $0.28 \mathrm{U}$ per side. After injection, the needle was maintained for a further 3 min to avoid back leakage. Finally, the skin was sutured using cyanoacrylate glue. After surgery, the animals were kept under controlled temperature and rehydrated with intraperitoneal injections of physiological fluid. The mice were then housed individually and were allowed $3 \mathrm{~d}$ for recovery before the experiment, i.e., before the diet change.

Hypothalamus dissection for $q P C R$ analysis. Once the mice had been killed, their brains were quickly removed and immersed for $10 \mathrm{~min}$ in 2 $\mathrm{ml}$ of ice-cold preservative medium (200 mM sucrose, $28 \mathrm{~mm} \mathrm{NaHCO}_{3}$, $2.5 \mathrm{~mm} \mathrm{KCl}, 7 \mathrm{~mm} \mathrm{MgCl}_{2}, 1.25 \mathrm{~mm} \mathrm{NaH}_{2} \mathrm{PO}_{4}, 0.5 \mathrm{~mm} \mathrm{CaCl}_{2}, 1 \mathrm{~mm}$ L-ascorbate, and $8 \mathrm{~mm}$ D-glucose, $\mathrm{pH} 7.4$ ) complemented with $10 \%$ RNAlater (Ambion). After incubation, the brains were mounted on a specimen plate using cyanoacrylate adhesive. The brains were then sliced using a vibratory microtome in a bath containing the chilled preservative medium with RNAlater. Five 500- $\mu$ m-thick serial coronal sections per brain were selected with the assistance of a mouse brain atlas, approximately from -3.0 to -0.5 to bregma. The slices were individually placed onto dishes containing $500 \mu \mathrm{l}$ of RNAlater. For the microdissection of the hypothalamus nuclei, each slice was placed on a $6 \%$ agarose bloc, covered with $50 \mu \mathrm{l}$ of RNAlater, and dissected under stereomicroscope and cold-light illumination, using a scalpel and sharp forceps. The arcuate nucleus (ARC), lateral hypothalamus area, and paraventricular nucleus were collected from two or three specific slices of the five, depending on their anteroposterior anatomical position. During the dissection, the harvested samples were placed on ice in $2 \mathrm{ml}$ centrifuge tubes containing $50 \mu \mathrm{l}$ of RNAlater. After removal of the RNAlater, the samples were finally stored at $-80^{\circ} \mathrm{C}$.
RNA extraction and processing. The tissues were lysed and homogenized in $300 \mu \mathrm{l}$ of lysis buffer (RLT Buffer, Qiagen) using the TissueLyser system (Qiagen) and $5 \mathrm{~mm}$ stainless steel beads (Qiagen). Total RNA was isolated on spin columns with silica-based membranes (RNeasy Mini Kit, Qiagen), following the manufacturer's instructions. DNA digestion was done directly on the columns. RNA was eluted with $30 \mu \mathrm{l}$ of $\mathrm{H}_{2} \mathrm{O}$. Aliquots of each extract $(1 \mu \mathrm{l})$ were checked for RNA concentration, purity and integrity with the Experion electrophoresis system (Bio-Rad) and the Experion RNA StdSens Analysis Kit (Bio-Rad). Total RNAs were then stored at $-80^{\circ} \mathrm{C}$. A small amount of purified RNAs $(0.2 \mu \mathrm{g})$ was reversetranscribed in $20 \mu \mathrm{l}$ of mixture using the High-Capacity cDNA Archive Kit (Qiagen), as indicated by the manufacturer. Synthesized cDNA were then stored at $-20^{\circ} \mathrm{C}$.

qPCR analysis by TaqMan low-density array. The low-density array (LDA) is a 384-well micro-fluidic card on which 384 simultaneous realtime PCRs can be performed (Applied Biosystems). Each custom card was configured as 8 -sample loading lines containing 48 reaction chambers. Gene-specific exon-spanning primers and TaqMan probes were factory-designed and embedded in each well. Analysis of one hypothalamic sample consisted in loading $100 \mu$ l of reaction mixture into one port of the LDA. The mixture comprised $15 \mu \mathrm{l}$ of synthesized cDNA (corresponding to $150 \mathrm{ng}$ of RNA), $50 \mu \mathrm{l}$ of TaqMan Gene Expression Master Mix (Applied Biosystems), and $35 \mu \mathrm{l}$ of water. After loading, the LDA was sealed and centrifuged twice for $2 \mathrm{~min}$ at $280 \times \mathrm{g}$. The LDA was placed in the 384-well block module of a thermal cycler (model 7900HT Fast Real-Time PCR system, Applied Biosystems). The PCR conditions were $2 \mathrm{~min}$ at $50^{\circ} \mathrm{C}$ and $10 \mathrm{~min}$ at $95^{\circ} \mathrm{C}$, followed by 40 cycles of $15 \mathrm{~s}$ at $95^{\circ} \mathrm{C}$ and $1 \mathrm{~min}$ at $60^{\circ} \mathrm{C}$. Raw fluorescence data were collected through the PCR using the SDS 2.3 software (Applied Biosystems), which further generated threshold cycles Ct with automatic determination of both baseline and threshold. After SDS software-assisted filtering of assays to discriminate aberrant PCR runs, the assays per hypothalamic area were: $n=9-12$ for STD, $n=6-7$ for HFD D1 (day 1), $n=6-7$ for HFD D3, and $n=5-6$ for HFD D8. The data were then analyzed with RQ Manager 1.2 software (Applied Biosystems) for relative quantitation. Relative quantitation of gene expression (RQ) was based on the comparative $\mathrm{Ct}$ method using the equation $\mathrm{RQ}=2^{-\Delta \Delta \mathrm{Ct}}$, where $\Delta \Delta \mathrm{Ct}$ for one gene target was its own Ct variation subtracted from a calibrator sample and normalized with an endogenous control. Precisely, polr $2 a$ was defined as the endogenous control after analysis of the most stable housekeeping gene using geNorm freeware, and one STD sample was arbitrarily chosen as a calibrator. Graphic representation of results was manually designed to assign one color for a $10 \%$ increment of gene expression relative to the STD group. Significant variation was noted with an asterisk.

Immunohistochemistry. The mice were anesthetized by intraperitoneal injection of ketamine/xylazine mix and then perfused intracardially with $4 \%$ paraformaldehyde solution. The brains were removed, postfixed at $4^{\circ} \mathrm{C}$ overnight, cryoprotected with $30 \%$ sucrose for $2 \mathrm{~d}$ at $4^{\circ} \mathrm{C}$, frozen in isopentane at $-60^{\circ} \mathrm{C}$, and finally stored at $-80^{\circ} \mathrm{C}$ until use. The hypothalamus was cut into $30 \mu \mathrm{m}$ serial sections with a cryostat (Leica). Five sections of the 15-18 harvested sections containing the arcuate nucleus were treated for immunohistochemistry. The sections were first blocked for 3-4 $\mathrm{h}$ and then incubated overnight at $4^{\circ} \mathrm{C}$ with anti-PSA (polysialic acid molecule) antibody (1:6000, \#AbC0019, EuroBio). After washing, the sections were then incubated in Alexa546-conjugated goat anti-mouse IgM (Invitrogen, 1:400) for $2 \mathrm{~h}$ at room temperature. After further washes, the sections were finally held with mounting medium and a coverslip.

Image acquisition and analysis. For densitometric analysis, immunolabeled sections were viewed on a confocal microscope (Leica SP2) under the $40 \times$ oil-immersion objective. Images of an immunostaining run (one animal of each condition: STD, HFD 1 d, HFD 3 d, HFD 8 d) were acquired with the same parameters ( $561 \mathrm{~nm}$ laser power, gain and offset of the photomultiplier). By using ImageJ software, the intensity of PSA labeling per section was bilaterally quantified on a selected area corresponding to the arcuate nucleus. Labeling intensity was measured on 5 sections per animal. The dentate gyrus was chosen as the control area. For the large-field study, sections were observed using an upright light microscope Axio Imager 2 (Zeiss) equipped with a motorized stage. Entire brain sections were scanned automatically under the $40 \times$ objective. 


\section{A Energy intake}

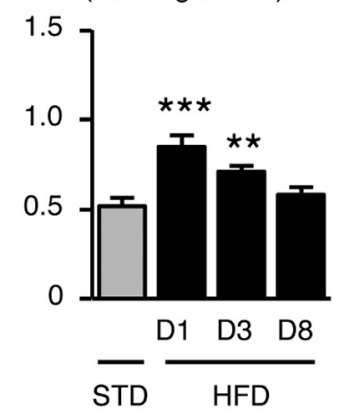

B

Triglycerides (mM)

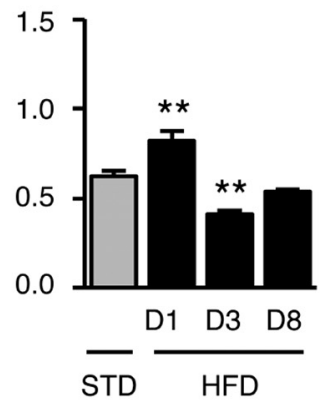

Free fatty acids (mM)

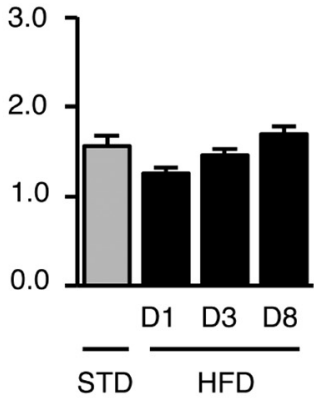

C D1

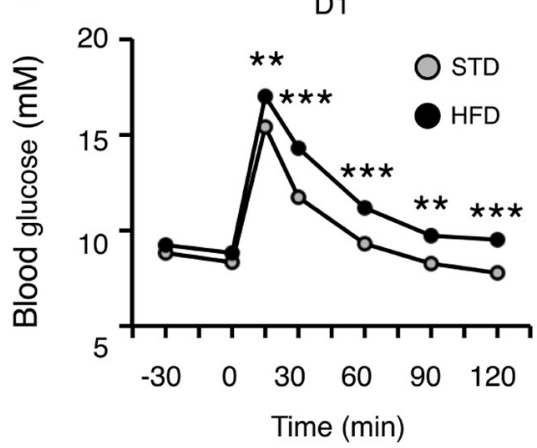

D

Respiratory exchange ratio

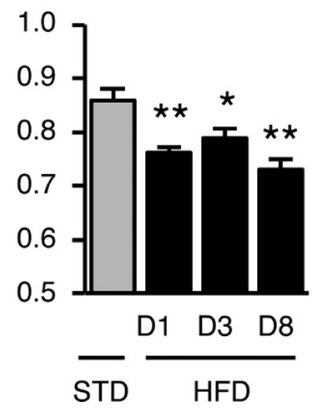

D3

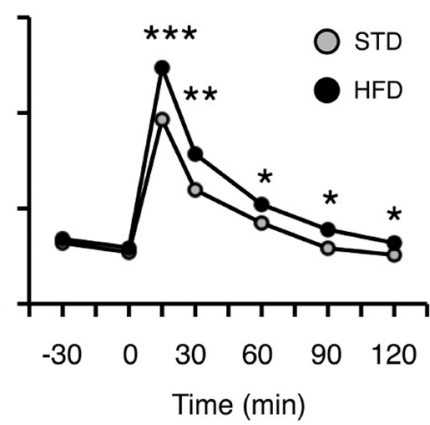

E

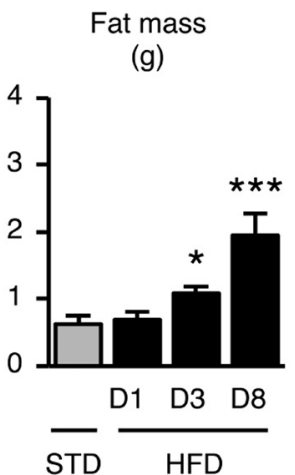

D8

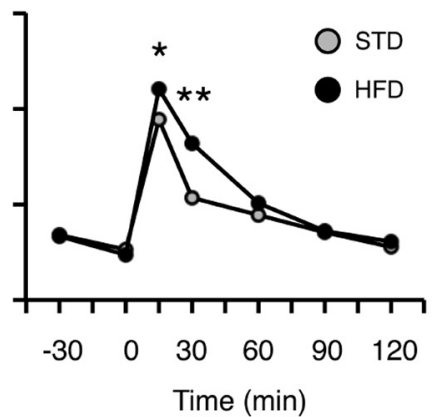

scut WAT mass

(\% of BW)

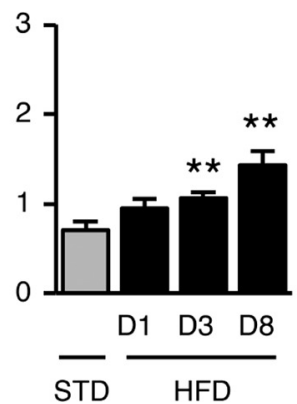

GIIS $(\mu \mathrm{U} / \mathrm{ml})$

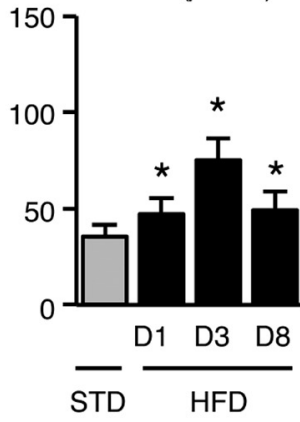

visc WAT mass

(\% of BW)

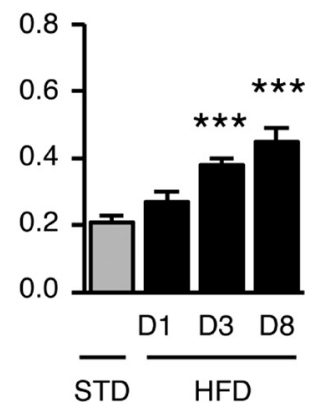

Figure 1. Energy intake and peripheral metabolism are transiently altered in mice fed HFD for 1 week. $\boldsymbol{A}-\boldsymbol{E}$, Energy intake $(\boldsymbol{A})$, plasma triglycerides and free fatty acid levels ( $\boldsymbol{B})$, glucose tolerance with glucose-induced insulin secretion (GIIS) (C), respiratory exchange ratio (D), and adiposity assessed by EchoMRI scan and subcutaneous (scut) and visceral (visc) fat pad weight after dissection (E) were measured in standard- and HFD-fed mice. D, Day. Data are means \pm SEM of $n=6-8$ animals per group. In all panels, groups were compared using Dunnett's test after ANOVA, with STD mice as the reference, or using the Mann-Whitney test when appropriate. Significant difference at ${ }^{*} p<0.05,{ }^{* *} p<0.01$, or ${ }^{* * *} p<0.001$, respectively.

Large high-resolution images were generated with Axiovision software and the MosaiX module (Zeiss).

Western blotting. Brains were removed and sliced in PBS using an acrylic matrix (WPI). The ventromedial hypothalami were dissected from one slice. Proteins were extracted in RIPA lysis buffer $(50 \mathrm{~mm}$ Tris- $\mathrm{HCl}$ pH 7.6, 150 mm NaCl, 1 mm EDTA, 1\% NP-40, 0.25\% sodium deoxycholate) supplemented with a protease inhibitor mix (Complete Mini, Roche), using the TissueLyser system (Qiagen) and $5 \mathrm{~mm}$ stainless steel beads (Qiagen). The homogenates were centrifuged at $5000 \times g$ for $5 \mathrm{~min}$, and the supernatants were collected and stored at $-80^{\circ} \mathrm{C}$ until use. The protein content of brain lysates was determined by the Lowry method (DC Protein assay kit; Bio-Rad Laboratories). Proteins $(10 \mu \mathrm{g}$ per lane) were separated by SDS/PAGE using $4-15 \%$ precast gels (MiniProtean TGX, Bio-Rad Laboratories), and transferred onto $0.2 \mu \mathrm{m}$ PVDF membranes (Trans-Blot Turbo mini PVDF transfer pack, Bio-Rad Laboratories) with the Trans-Blot Turbo system (Bio-Rad Laboratories). After blocking with 5\% nonfat milk in TBST (Tris-buffered salineTween 20; $20 \mathrm{~mm}$ Tris, $150 \mathrm{~mm} \mathrm{NaCl}, 0.1 \%$ Tween 20, pH 7.6) for $1 \mathrm{~h}$ at room temperature, the membranes were probed at $4^{\circ} \mathrm{C}$ overnight with rabbit polyclonal anti-PSA antibody (1:10,000; \#AbC0019; Eurobio), diluted in TBST with $1 \%$ nonfat milk. The blot was rinsed in TBST $(3 \times 5$ $\mathrm{min}$ ) and was further incubated with HRP-conjugated secondary antibody anti-IgG for $1 \mathrm{~h}$ (1:10,000 in TBST; \#NA931V; GE Healthcare) and soaked in a luminol-contained mix (ImmunStar WesternC Chemiluminescence kit, Bio-Rad Laboratories). The enhanced chemiluminescent signal of the blot was detected in a darkroom with a CCD camera (Molecular Imager Gel Doc XR System; Bio-Rad). The volume of the bands (i.e., area $\times$ intensity) was quantified using Quantity One software (Bio-Rad). To ensure equality in the protein loading, the membranes were also probed with a rabbit polyclonal $\beta$-actin antibody (1:10,000; \#\#MAB1501; Millipore).

Electrophysiological recordings. Brain slices $(300 \mu \mathrm{m})$ were prepared from adult POMC-GFP (pro-opiomelanocortin-green fluorescent protein) mice (6-8 weeks old). The slices were incubated at room temperature in oxygenated extracellular medium containing (in mM): $118 \mathrm{NaCl}, 3 \mathrm{KCl}, 1 \mathrm{MgCl}_{2}, 25$ $\mathrm{NaHCO}_{3}, 1.2 \mathrm{NaH}_{2} \mathrm{PO}_{4}, 1.5 \mathrm{CaCl}_{2}, 5$ HEPES, 5 D-glucose, 15 sucrose (300- 
A

A Relative expression compared to STD (\%)
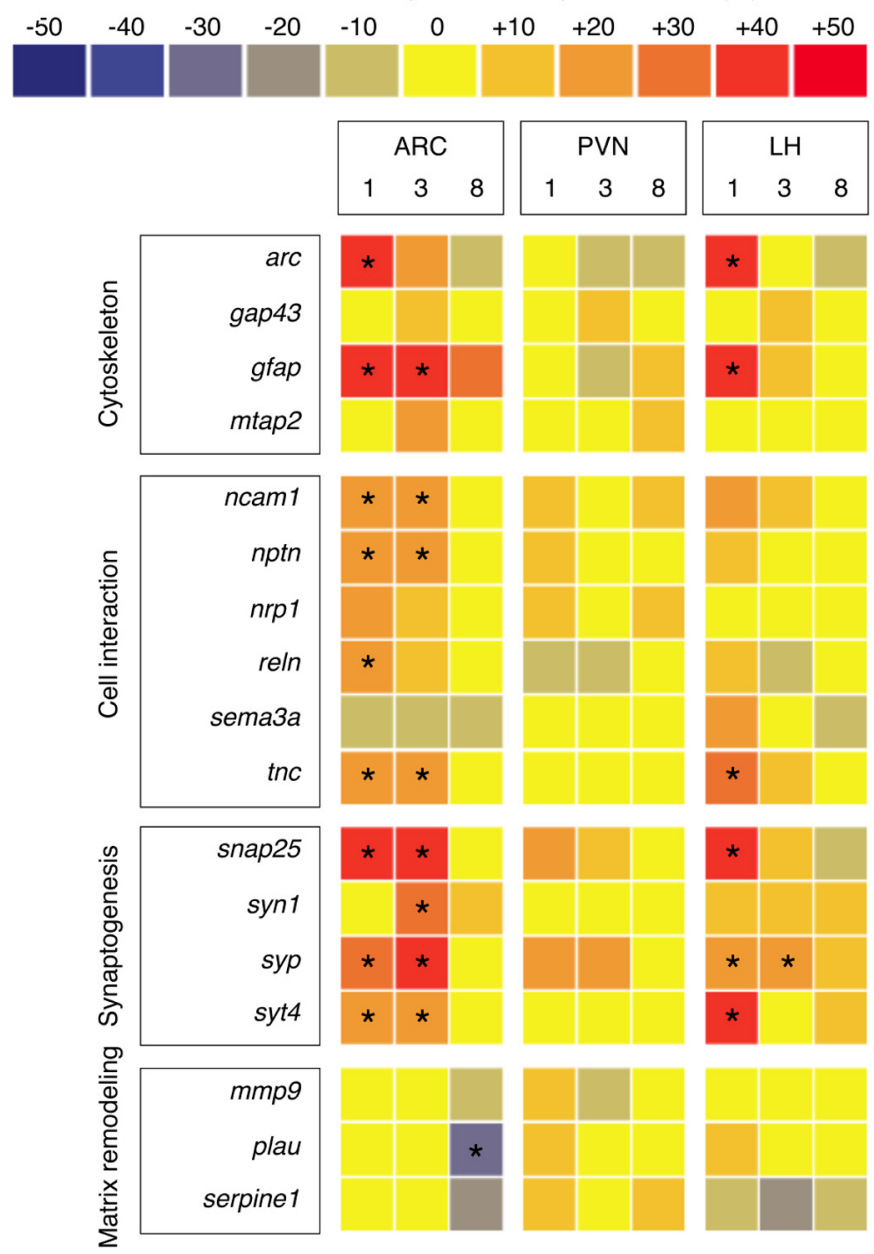

B

PSA immunoreactivity
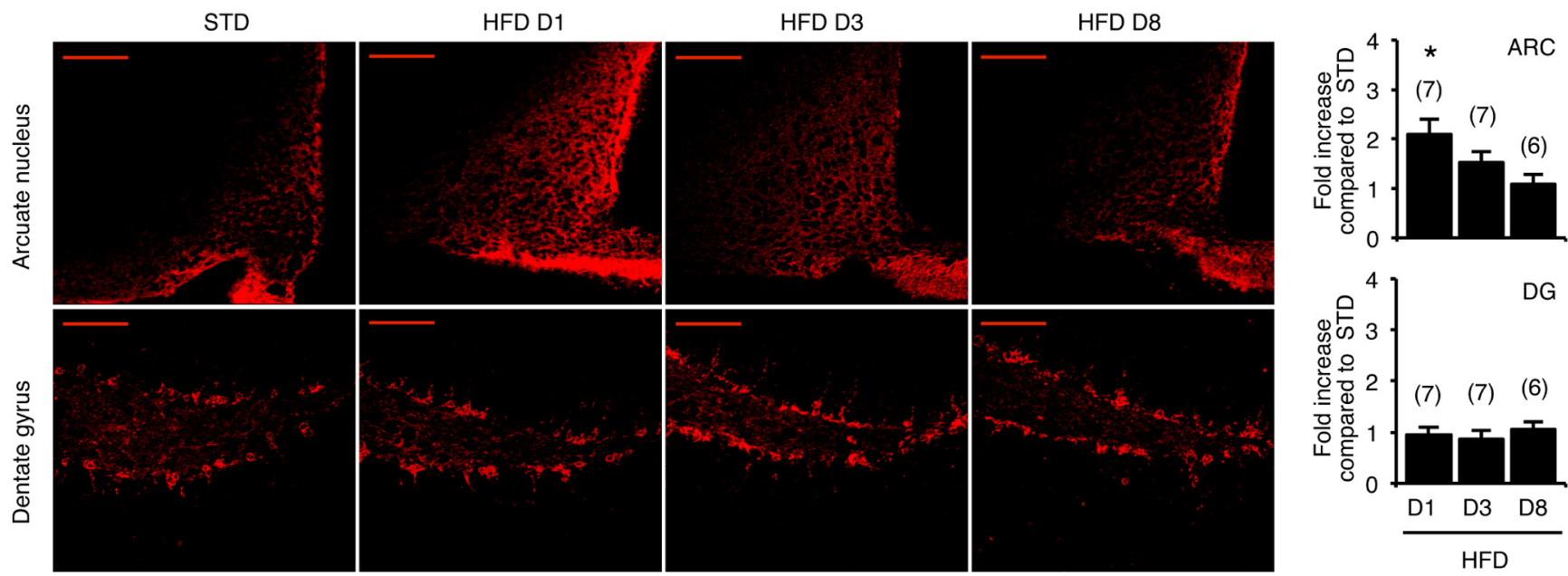

Figure 2. Hypothalami from mice fed an HFD for 1 d exhibit the molecular signature of plasticity. $A$, Simultaneous quantification of the expression of genes in hypothalamic biopsies using Taqman low density arrays. $\boldsymbol{B}$, Representative PSA immunostaining in arcuate nucleus and dentate gyrus of standard- and HFD-fed mice. Scale bar, $100 \mu \mathrm{m}$. D, Day; ARC, arcuate nucleus; PVN, paraventricular nucleus; LH, lateral hypothalamic area; DG, dentate gyrus. Data are means \pm SEM. In $\boldsymbol{A}$ and $\boldsymbol{B}$, groups were compared using Bonferroni's test after ANOVA. Regarding the gene expression study, individual analysis was conducted for each gene. Significant difference at ${ }^{*} p<0.05$.

$310 \mathrm{mOsm}, \mathrm{pH}$ 7.4) for a recovery period. Once in the recording chamber, the slices were perfused at $2-3 \mathrm{ml} / \mathrm{min}$ with the same extracellular medium. Viable ARC neurons were viewed using a $40 \times$ water-immersion objective (Nikon) under IR-DIC illumination and an infrared video camera (Hamamatsu Photonics). GFP-positive neurons were visualized using epi- fluorescence and specific filter sets (AHF analysentechnik AG). For EPSC recordings, borosilicate pipettes (4-6 M $\Omega$; GC150F-10, Phymep) were filled with a potassium-gluconate-based solution containing (in $\mathrm{mM}$ ): $155 \mathrm{~K}$ gluconate, 0.1 EGTA, $1 \mathrm{CaCl}_{2}, 10 \mathrm{HEPES}, 5 \mathrm{KCl}, 10 \mathrm{KOH}, 4 \mathrm{Mg}$-ATP, 0.25 Na-GTP (290 mOsm, pH 7.3). The extracellular medium was supplemented 
with picrotoxin $(100 \mu \mathrm{M})$ to block GABAergic IPSCs. For IPSC recordings, pipettes were filled with a cesium-chloride solution containing (in mM): $140 \mathrm{CsCl}, 3.6 \mathrm{NaCl}, 1 \mathrm{MgCl}_{2}, 10$ HEPES, 0.1 $\mathrm{Na}_{4}$ EGTA, 4 Mg-ATP, 0.25 Na-GTP (290 mOsm, pH 7.3). A mixture of 6-cyano-7-nitroquinoxaline-2,3-dione $(20 \mu \mathrm{M})$ and $(2 R)$-amino-5-phosphonovaleric acid $(50 \mu \mathrm{M})$ was added to the extracellular medium to block glutamatergic currents. Miniature EPSCs and IPSCs were isolated and monitored by adding tetrodotoxin (TTX, $500 \mathrm{~nm}$ ) to the extracellular solution. The recordings were made using an Axopatch $1 \mathrm{D}$ amplifier, digitized using the Digidata 1320A interface and acquired using pClamp 9.2 software (Molecular Devices). The pipettes and cell capacitances were fully compensated. Access resistance was monitored over the course of the recordings. Cells were excluded if the access resistance was $>35 \mathrm{M} \Omega$ and/or increased significantly (>20\% of change) during the experiment. Cells were voltage clamped at $-60 \mathrm{mV}$, and sampled at a frequency of $10 \mathrm{kHz}$. Currents were recorded for at least $5 \mathrm{~min}$. EPSC and IPSC frequency was calculated over a period of at least $150 \mathrm{~s}$ using Clampfit software (Molecular Devices).

Statistical analysis. All data are expressed as means. Error bars indicate SEM. Multiple comparisons of groups were performed by a one-way ANOVA using Prism 4.0 software (GraphPad Software). Post hoc analyses were used when main effects reached significance without any mathematical correction. Before analysis, Bartlett's and Shapiro-Wilk's tests were applied to check equality of variances and to evaluate the normality of distribution, respectively. Bonferroni's, Newman-Keuls', or Dunnett's tests were used to compare groups. Student's $t$ test was used when only two groups (STD vs HFD) were studied. When variances were significantly different, the Mann-Whitney test was applied. Significant difference was noted on the graphic representation when $p$ value was $<0.05,0.01$, or 0.001 .

\section{Results}

Homeostatic response to HFD feeding We first characterized the model of shortterm HFD used in this study (see Table 1 for information regarding diets). In 8-week-old mice, feeding HFD ad libitum rapidly increased energy intake: $0.85 \pm 0.06$ $\mathrm{kcal} / \mathrm{d} / \mathrm{g}$ body weight after $24 \mathrm{~h}$ versus $0.52 \pm 0.05 \mathrm{kcal} / \mathrm{d} / \mathrm{g}$ in mice maintained on a standard diet. However, this HFD-induced energy intake was transient and reversed in a week even under the persistent diet challenge (Fig. $1 A ; F_{(3,24)}=10.50 ; p<0.001$ for HFD D1 and $p<0.01$ for HFD D3, determined using one-way ANOVA and Dunnett post hoc test against STD). In other words, food intake progressively fell after introduction of the HFD and was stabilized after a week (from $0.18 \pm 0.02$ to $0.12 \pm 0.02 \mathrm{~g} / \mathrm{d} / \mathrm{g}$ body weight). In addition, the ingestion of dietary fat rapidly caused metabolic impairments such as elevated plasma triglyceride levels, and marked glucose intolerance (Fig. $1 B, C$ ) as fully described by others (Butler et al., 2001; Wang et al., 2001; Pocai et al., 2005, 2006). Again, these alterations were reversed in a week. Finally, a shift in substrate utilization from carbohydrates to lipids was detected after only $24 \mathrm{~h}$ on the HFD (STD: $0.86 \pm 0.04$; HFD D1: $0.77 \pm 0.02$; Fig. $1 D ; F_{(3,22)}=7.57 ; p<0.05$ for HFD
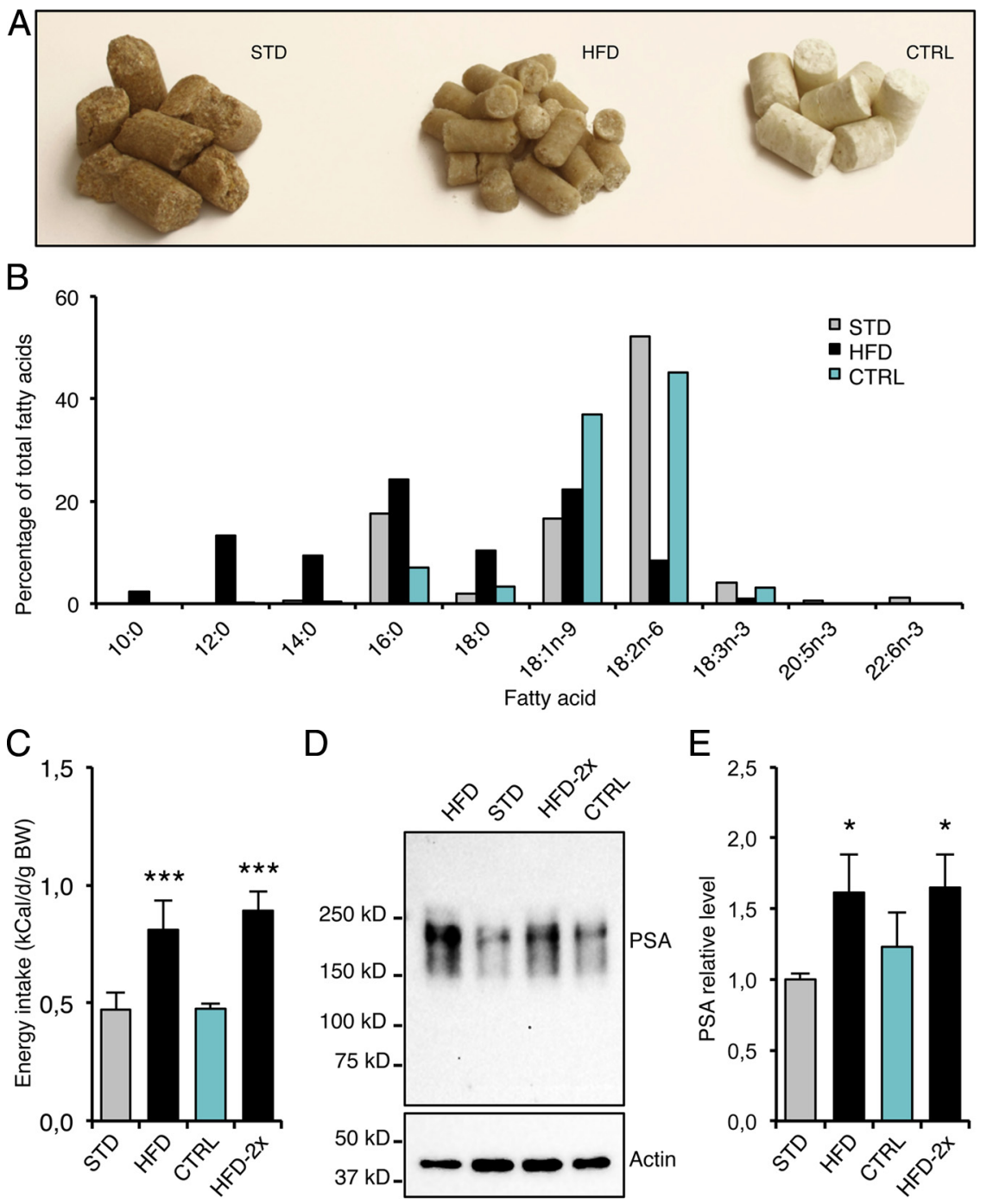

Figure 3. Food novelty is not sufficient to stimulate PSA production in the hypothalamus. $A$, Photograph of STD, HFD, and CTRL iets. $\boldsymbol{B}$, Fatty acid composition of diets, as determined by gas chromatography. $\boldsymbol{C}$, Energy intake after STD, CTRL, or HFD feeding for

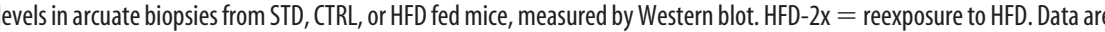
means \pm SEM of $n=9$ (STD), 5 (HFD), 7 (CTRL), and 7 (HFD-2x). In C and $\boldsymbol{E}$, groups were compared using the Mann-Whitney test. Significant difference at ${ }^{*} p<0.05$ or ${ }^{* * *} p<0.001$, respectively.

D1, HFD D3, and HFD D8, determined using one-way ANOVA and Dunnett's post hoc test against STD), and adiposity was increased on the third day (fat mass STD: $0.63 \pm 0.13$; fat mass HFD D3: $1.08 \pm 0.11$ g; Fig. $1 E$; $p<0.05$ for HFD D3, $p<0.001$ for HFD D8, determined using the Mann-Whitney test against STD), suggesting appropriate nutrient channeling and efficient storage of the energy overload. We concluded that the mice rapidly adapted their eating behavior and metabolism to the hypercaloric nutritional condition. Indeed, this model constitutes a paradigm of homeostatic control in response to dietary fat, as suggested by Butler et al. (2001).

\section{Molecular signature of brain plasticity is induced in the hypothalamus after HFD feeding}

The adaptive response to sustained external stimuli or durable physiological modification can be linked to tissue rearrangement in specific brain areas (Hübener and Bonhoeffer, 2010; McEwen, 2010). These activity-dependent modifications are based on the co- 
A

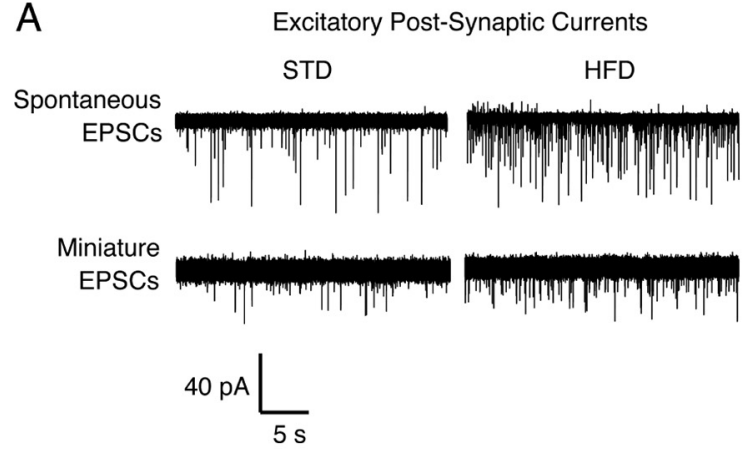

B

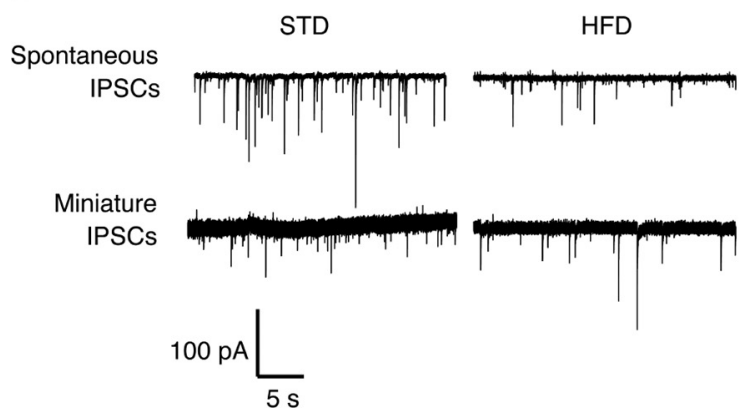

EPSCs Frequency $(\mathrm{Hz})$

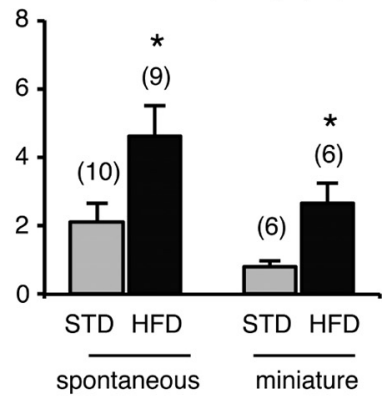

IPSCs Frequency $(\mathrm{Hz})$

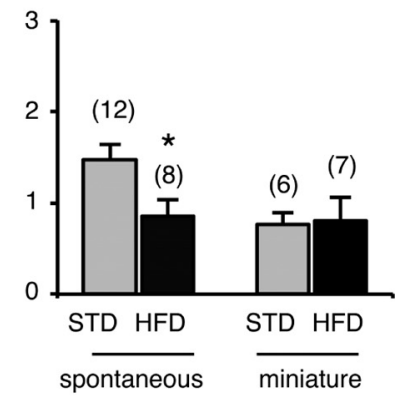

Figure 4. Arcuate POMC neurons of mice fed an HFD for $3 \mathrm{~d}$ are rewired. Postsynaptic excitatory $(\boldsymbol{A})$ and inhibitory $(\boldsymbol{B})$ currents in GFP-tagged POMC neurons from standard mice and mice fed an HFD for $3 \mathrm{~d}$ were recorded in a whole-cell voltage-clamp configuration (holding potential at $-60 \mathrm{mV}$ ). Representative sample traces $(30 \mathrm{~s}$ ) are given in each panel. Frequencies of spontaneous and miniature currents were calculated before and after adding TTX, respectively. Data are means \pm SEM. Groups were compared using Student's $t$ test. Significant difference at ${ }^{*} p<0.05$.

ordinated regulation of mRNA expression (Bramham and Wells, 2007) and protein synthesis (Cajigas et al., 2010). To determine whether HFD feeding induces plasticity within the hypothalamus, we measured the relative expression of several permissive factors of brain plasticity in dissected hypothalamic areas (i.e., arcuate nucleus, paraventricular nucleus and lateral hypothalamus) using lowdensity arrays. Screening was performed after 1, 3, and $8 \mathrm{~d}$ of HFD feeding. Compared with standard-diet-fed mice, mRNA abundance of a cluster of plasticity markers $(n=10)$ was significantly increased in biopsies from HFD-fed mice (from 10 to 40\%) (Fig. 2 A; statistical significance determined using one-way ANOVA and Bonferroni post hoc test, or using Mann-Whitney test when variances were unequal). This change was rapid and transient, occurring after 1 and $3 \mathrm{~d}$ of HFD feeding, and was mostly located in the arcuate nucleus. We found upregulation of ncam1, nrp 1, tnc, snap25, syp, syt4, suggesting that HFD modified cell interactions and induced synaptogenesis. By contrast, expression of gap43, serpine1, mmp9, or plau was not affected suggesting no change in axonal sprouting. Changes in cell interactions can be mediated by the polysialic acid (PSA) molecule (Rutishauser, 2008). PSA is a cell-surface glycan with a large hydrated volume that modulates distances between cells. Basically, the attachment of PSA to membrane proteins, such as the neural cell-adhesion molecule (NCAM), promotes synaptic reorganization and other plasticity-related events by weakening cell-to-cell interactions. We therefore examined levels of PSA in adult brains from standard- and HFD-fed mice. The brains were fixed, sectioned and analyzed for the abundance of PSA by immunohistochemistry. A twofold increase in arcuate PSA immunoreactivity was calculated from optical sections acquired by confocal laser scanning microscope (Fig. $2 B ; F_{(3,24)}=4.67 ; p<0.05$ for HFD D1, determined using one-way ANOVA and Bonferroni post hoc test), whereas no variation was detected in the dentate gyrus of the hippocampus, the most frequently described brain area able to undergo remodeling.

\section{Novelty is not sufficient to induce PSA} in the arcuate nucleus

The molecular signature of plasticity that is detected in the hypothalamus after HFD feeding could be induced by the change in food composition or merely by the stress linked to the novelty. We therefore tested whether the replacement of food was sufficient to stimulate PSA expression in the arcuate nucleus. A standard diet was replaced by an isolipidic isocaloric control (CTRL) diet, whose composition was similar but which differed in appearance, in texture, and probably in flavor (Fig. $3 A, B)$. Introduction of the CTRL diet did not modify the energy intake of mice (Fig. $3 C)$. One day after feeding with the STD, HFD or CTRL diet, PSA abundance was measured in protein extracts from arcuate nuclei by Western blot (Fig. 3D). Again, the HFD for $1 \mathrm{~d}$ increased PSA levels in the arcuate nucleus (Fig. $3 E ; p<0.05$, determined using the Mann-Whitney test against STD). By contrast, the CTRL diet did not modify the PSA level. Moreover, after $6 \mathrm{~d}$ on the STD diet, $24 \mathrm{~h}$ of reexposure to the HFD still increased energy intake (Fig. $3 C ; p<0.001$, determined using the Mann-Whitney test against STD), and increased the PSA level in arcuate biopsies (Fig. 3E; $p<0.05$, determined using the Mann-Whitney test against STD). Together, these results indicate that novelty in food conditions alone is not sufficient to increase PSA levels in the hypothalamus.

\section{HFD feeding for $3 \mathrm{~d}$ induces arcuate POMC neuron rewiring}

The melanocortin system in the CNS plays a fundamental role in the regulation of energy homeostasis by producing anorexigenic effects when stimulated (Cone, 2005; Berthoud and Morrison, 2008). The response controlled by POMC neurons is actually defined by their intrinsic neuronal activity and synaptic inputs. Interestingly, these inputs can be rapidly rewired (Pinto et al., 2004; Sternson et al., 2005). To investigate whether the HFD challenge could affect presynaptic inputs on arcuate POMC neurons, we recorded the frequencies of spontaneous and miniature postsynaptic currents (sPSCs and mPSCs) in arcuate GFP-tagged POMC neurons held in the whole-cell voltage-clamp configuration, using brain slices from mice fed either a standard diet or HFD for $3 \mathrm{~d}$. We found an increase in the frequency of spontaneous EPSCs (sEPSCs) on arcuate POMC neurons in HFD mice (STD: $2.12 \pm 0.55 \mathrm{~Hz}$; HFD: $4.63 \pm 0.87 \mathrm{~Hz}$; Fig. $4 A$; $p<0.05$, determined using $t$ test). By contrast, the frequency of spontaneous IPSCs was decreased in HFD fed mice (STD: $1.47 \pm 0.17 \mathrm{~Hz}$; HFD: $0.86 \pm 0.17 \mathrm{~Hz}$; Fig. $4 B$; $p<0.05$, determined using $t$ test). We also quantified the frequency of mPSCs arising from spontaneous vesicle fusion by using TTX to block all action potentialdriven PSCs. The quantification of mPSC frequency gives an indirect estimation of the number of synapses onto postsynaptic neurons. Miniature EPSC (mEPSCs) frequency was increased 
after HFD feeding whereas miniature IPSC (mIPSCs) frequency was not changed (mEPSCs: STD: $0.81 \pm 0.16 \mathrm{~Hz}$ vs HFD: $2.66 \pm 0.57 \mathrm{~Hz}$; mIPSCs: STD: $0.76 \pm 0.14 \mathrm{~Hz}$ vs HFD: $0.80 \pm 0.26 \mathrm{~Hz}$; Fig. $4 A, B ; p>0.05$, determined using $t$ test). No significant differences were observed in the amplitude of either sPSCs or mPSCs after the HFD challenge (sPSCs: STD: $18.25 \pm 1.49$ vs HFD $17.32 \pm 3.77$ pA; mPSCs: STD: $11.19 \pm 0.87$ vs HFD $11.54 \pm 0.72 \mathrm{pA})(p>0.05$, determined using a $t$ test). Together, these data suggest the reorganization of synapses onto arcuate POMC neurons after $3 \mathrm{~d}$ of HFD, thus increasing the excitatory inputs on these cells. A higher anorexigenic tone from POMC neurons is consistent with the progressive decrease in energy intake observed after HFD introduction.

PSA is required for POMC rewiring and the homeostatic response to dietary fat We next examined the role of PSA in dietinduced hypothalamic plasticity using the enzyme EndoN, which specifically removes PSA residues from NCAM isoforms (Vimr et al., 1984). We injected EndoN bilaterally into the ventral hypothalamus by stereotaxy. Three days after surgery, the mice were fed a standard or an HFD. Microscopic observation of brains $3 \mathrm{~d}$ after surgery revealed that EndoN totally removed PSA immunoreactivity in the whole hypothalamus of HFD-fed mice (Fig. 5B). The EndoN-induced PSA washout persisted for at least 1 week. EndoN injection fully inhibited the increase in the frequency of sEPSCs and mEPSCs onto POMC neurons previously observed in uninjected mice fed an HFD for $3 \mathrm{~d}$ (sEPSCs: $1.49 \pm 0.51 \mathrm{~Hz}$; mEPSCs: $0.65 \pm 0.12$ $\mathrm{Hz})(p<0.05$, determined using a $t$ test $)$.

To investigate whether diet-induced POMC rewiring was involved in the maintenance of energy balance, we quantified energy intake in EndoN-treated animals. Mice receiving either vehicle or EndoN maintained a constant energy intake when fed a standard diet $(\approx 0.50 \mathrm{kcal} / \mathrm{d} / \mathrm{g} ;$ Fig. $5 C)$. As before, energy intake was increased in mice fed an HFD for $1 \mathrm{~d}$ in both treatments, reaching $0.80 \mathrm{kcal} / \mathrm{d} / \mathrm{g}$ approximately. However, mice receiving EndoN were still overfed after 1 week on the HFD and their cumulative energy intake was higher $(+9.2 \%)$ than that of vehicle-treated mice (Fig. $5 D ; F_{(3,71)}=59.68$; $p<0.001$, determined using one-way ANOVA and Newman-Keuls post hoc test). Moreover, EndoN-treated mice displayed a greater body weight gain after 1 week (HFD+EndoN: $1.52 \pm 0.19 \mathrm{~g}$; HFD+vehicle: $0.90 \pm 0.14$ g; Fig. $5 E ; F_{(3,71)}=13.95 ; p<0.01$, determined using one-way ANOVA and Newman-Keuls post hoc test). Despite this, EndoN treatment did not directly affect glucose tolerance (Fig. 5F). As before (Fig. 1B), glucose tolerance was not totally recovered after HFD feeding for $8 \mathrm{~d}$. EndoN did
A

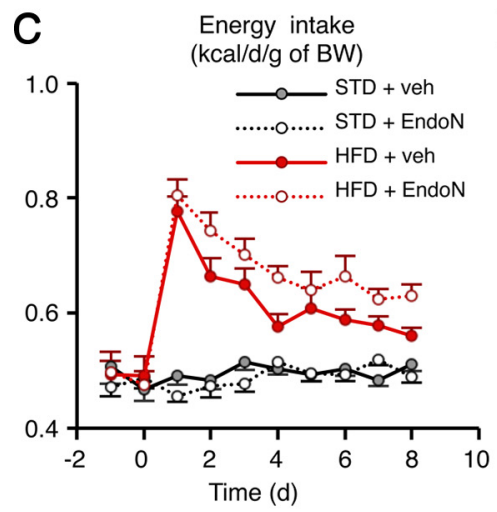

D Cumulative energy intake
(kcal/g of BW)
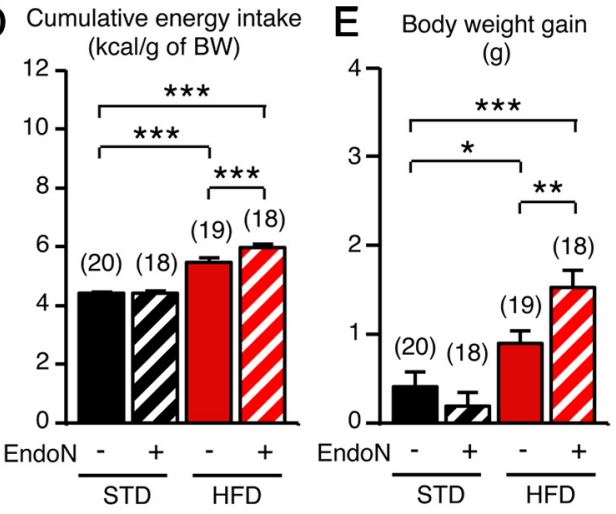

F

AUC (au)

GIIS $(\mu \mathrm{U} / \mathrm{ml})$
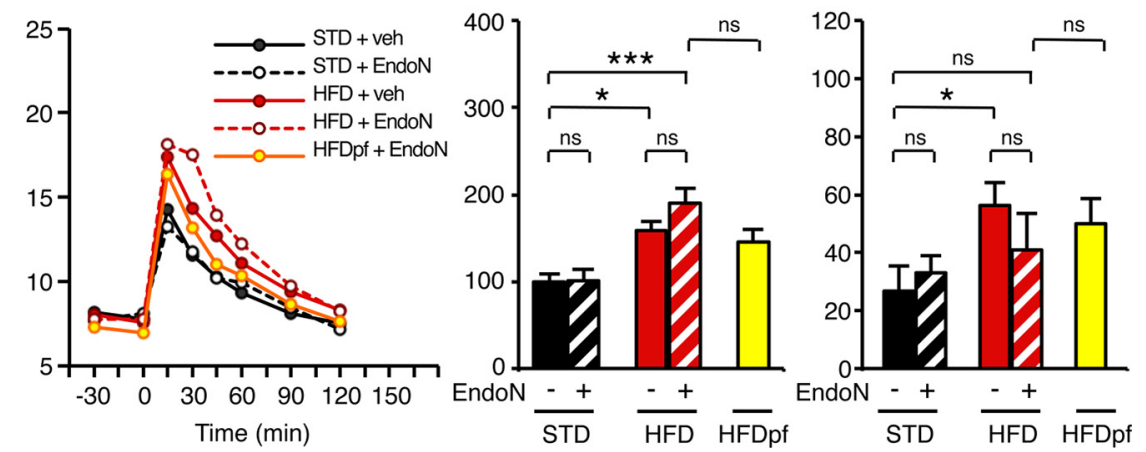

Figure 5. PSA removal in the hypothalamus impairs the homeostatic control of energy intake after HFD introduction. $\boldsymbol{A}$, Experimental paradigm to remove PSA in the hypothalamus and assess energy balance in mice fed an HFD or not. $\boldsymbol{B}$, Pictures show representative brain sections with a complete washout of PSA immunoreactivity after endoneuraminidase injection. Scale bar, 2 mm. $\mathbf{C} \boldsymbol{F}$, Energy intake (C)

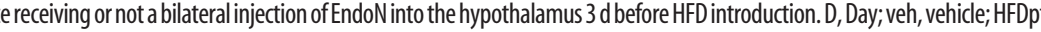
high fat diet, pairfed; AUC, area under curve; GIIS, glucose-induced insulin secretion. Data are means \pm SEM. Groups were compared using the Newman-Keuls test after ANOVA. Significant difference at ${ }^{*} p<0.05$, ${ }^{* *} p<0.01$, or ${ }^{* * *} p<0.001$, respectively.

not alter glucose tolerance in STD mice. In HFD-fed mice, EndoN treatment produced a minor but nonsignificant increase in glucose intolerance. This slight effect was probably due to the EndoN-induced increase in dietary fat ingestion, because tolerance values were similar when EndoN-treated HFD-fed animals were pair-fed with the HFD-veh group.

To further assess the role of PSA in the regulation of energy intake, we compared physiological responses to HFD in wildtype and PST-1 knock-out mice $\left(\right.$ St8sia $\left.4^{-1-}\right)$. These mice lack the ST8SiaIV (or PST-1) enzyme, a polysialyltransferase responsible for the addition of PSA to NCAM (Eckhardt et al., 2000). No increase in arcuate PSA immunoreactivity was detected in adult mutant mice after HFD introduction (Fig. 6A). In wild-type and mutant mice, daily energy intake was identical $(0.53 \pm 0.03 \mathrm{kcal} /$ 
A

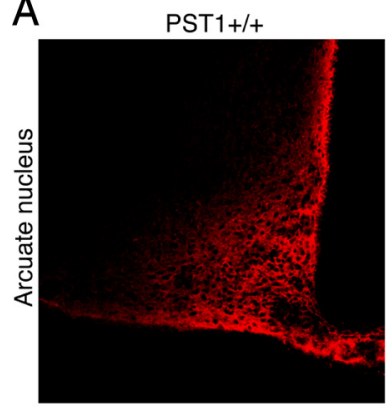

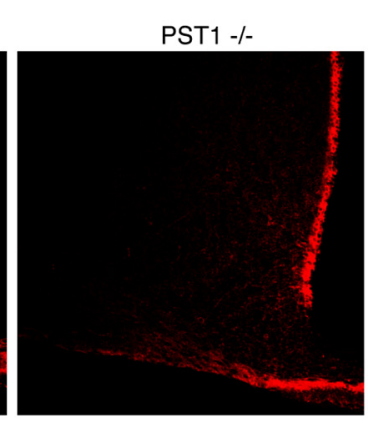

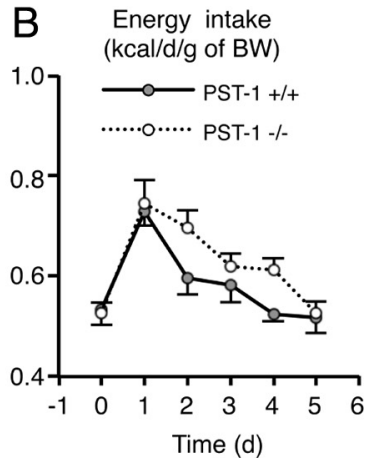

Figure 6. PST-1 enzyme deficiency impairs the homeostatic control of energy intake after HFD introduction. $\boldsymbol{A}$, Representative PSA immunostaining in arcuate nucleus of PST- $1^{+/+}$and PST- $1^{-1-}$ mice fed an HFD for $1 \mathrm{~d}$. $\boldsymbol{B}$, Energy intake of PST- $1^{+/+}$and PST- $1^{-1-}$ mice fed an HFD for 5 d. Data are means \pm SEM. $n=6$ PST- $1^{+/+}$mice and $n=12$ PST- $1^{-l-}$ mice. Groups were compared using Student's $t$ test.

d/g; Fig. 6B). Moreover, energy intake of wild-type and mutant mice increased similarly on day 1 after HFD introduction $(0,73 \pm$ 0.03 and $0,75 \pm 0.05 \mathrm{kcal} / \mathrm{d} / \mathrm{g}$, respectively). However, in mutant mice the return to basal level took $1 \mathrm{~d}$ longer than in wild-type mice. Consequently, the cumulative energy intake was increased by $8.6 \%$ in mutant mice fed for $5 \mathrm{~d}$ with HFD compared with their wild-type littermates (wild-type: $2.95 \pm 0.09 \mathrm{kcal} / \mathrm{g}, \mathrm{KO}$ : $3.20 \pm 0.07 \mathrm{kcal} / \mathrm{g} ; p<0.05$, determined using $t$ test). Body weight gain of HFD-fed mutant mice was not significantly increased (wild-type: $0.38 \pm 0.22 \mathrm{~g}$, KO: $0.69 \pm 0.14 \mathrm{~g}$ ), probably exposure to the HFD was too short. These results demonstrate that the PST1 enzyme plays a role in the behavioral adaptation to HFD.

\section{Discussion}

Hypothalamic plasticity could be defined as an adaptive process aimed at integrating changes in environmental conditions and physiological states (Oliet, 2002; Prevot, 2002; Ebling and Barrett, 2008). Here, we report that a change of diet is another situation leading to hypothalamic neuronal network rewiring. Indeed, persistent fat ingestion increases the frequency of miniature excitatory postsynapic currents in POMC neurons, which strongly suggests a synaptic reorganization on these cells (Pinto et al., 2004). In this study, we did not find the causative link between these electrophysiological data and the modification of food intake after HFD introduction, which requires inducible and targeted inhibition of PSA-mediated synaptogenesis in POMC cells. However, (1) PSA overexpression precedes behavioral changes, (2) both, HFD-induced POMC rewiring and the progressive restoration of energy intake are EndoN sensitive, and (3) anorexigenic POMC neurons are thought to be involved in adaptive homeostatic processes that maintain energy homeostasis (Cone, 2005). As a result, the HFD-induced PSA-dependent POMC rewiring could explain the homeostatic response to dietary fat.

Although the role of the melanocortin system in the adaptation of food intake in response to variations in nutritional conditions has been already proposed (Butler et al., 2001; Pillot et al., 2011), synaptic reorganization on arcuate POMC neurons now has to be considered a key component in the physiological feedback. Nevertheless, we cannot exclude either a synergic effect due to mirror synaptic rewiring of orexigenic cells, NPY/AgRP neurons for instance. Additional defenses against metabolic imbalance also involve nonsynaptic mechanisms, such as the HFD-stimulated upregulation of POMC expression (Ziotopoulou et al., 2000). As cell turn-over in feeding circuits is inhibited in obese mice (McNay et al.,
2012), hypothalamic cell renewal might also contribute to the homeostatic response to dietary fat. Therefore the homeostatic control of energy balance is surely consolidated by a combination of several plasticityrelated processes from rapid pharmacological to slower morphological changes. Unfortunately, all of these brain safety mechanisms are obviously overtaken when the calorific pressure is sustained.

Interestingly, the molecular screening of plastic events in the hypothalamus of HFD mice using low-density arrays suggests a brief and arcuate-specific modification in cell interactions. Although the melanocortin system is a widespread neuronal network, diet-induced synaptic plasticity seems to affect arcuate, probably first-order, neurons only. Therefore, downstream targets of arcuate POMC or AgRP neurons such as paraventricular MC4R-positive neurons, which are crucial in the homeostatic response to dietary fat (Butler et al., 2001), could relay the increased anorexigenic tone from the arcuate nucleus without particular synaptic remodeling.

In this article, we report a PSA-dependent control of body weight. The obesogenic effect of EndoN could be linked to an alteration in food intake regulation, but an effect on energy expenditure is not excluded either. Indeed, POMC neurons also govern "facultative" thermogenesis, which burns off excess calories during times of plenty. On the other hand, the restoration of glucose tolerance is not EndoN sensitive, suggesting that PSAdependent neuronal rewiring is not crucial to maintain glucose homeostasis. Thus, PSA-dependent hypothalamic plasticity appears to act on specific physiological responses such as the regulation of food intake. This was unexpected, given the broad spectrum of action of the melanocortin system on peripheral metabolism (Mountjoy, 2010). However, to our knowledge, hormonal stimulation of POMC neuron rewiring does not alter glucose homeostasis either.

It appears that synaptic activity on POMC neurons promotes a homeostatic response to dietary fat ingestion, i.e., the progressive reduction of food intake over a week. The change in hypothalamic neuron connectivity persists for several months even though the HFD continues (Horvath et al., 2010). However, the different outcomes in short- and long-term exposure to HFD could be linked to leptin resistance in diet-induced obese animals, a situation in which elevated leptin levels no longer sustain POMC neuronal firing (Cowley et al., 2001; Enriori et al., 2007; Diano et al., 2011).

We identified PSA as a downstream actor required for the diet-induced rewiring of POMC neurons. Polysialylation is a ubiquitous mechanism found in several hypothalamic processes that involve modifications in cell interactions (Theodosis et al., 1991). Therefore, it is probably not specific to the diet-dependent synaptic plasticity of arcuate POMC neurons. Rather, it could be considered a common permissive process that might be recruited in other previously described hormone-dependent rewiring of these neurons (Pinto et al., 2004; Gao et al., 2007; Gyengesi et al., 2010; Yang et al., 2011). In addition, according to the transcriptomic assay, other regulators of dynamic cell interactions and synaptogenesis might also be involved in diet-induced hypothalamic plasticity. Indeed, syndecan-3 and synaptotagmin-4 are 
promising targets to control obesity and related diseases (Strader et al., 2004; Zhang et al., 2011).

Biological mediators that promote diet-induced hypothalamic plasticity have not been investigated in this study, but one can easily speculate that metabolic hormones, which act on the energy metabolism through their neurotrophic properties, might be involved in this physiological mechanism (Pinto et al., 2004; Abizaid et al., 2006; Coppola et al., 2007; Andrews et al., 2008; Chiu and Cline, 2010; Yang et al., 2011). Leptin is one of the putative candidates. Blood leptin levels promptly increased after $3 \mathrm{~d}$ of HFD (Wang et al., 2001). This is consistent with the fat mass expansion detected in our model. Therefore, leptin could promote the synaptic reorganization of POMC neurons to inhibit food intake in addition to its direct stimulating effect on POMC neuronal activity. The contribution of nutrients themselves and/or their metabolites in this process should be considered too. For instance, dietary fat-derived endocannabinoids are major components of the gut-brain axis and can engender synaptic alterations in the brain (Crosby et al., 2011; Lafourcade et al., 2011; Bermudez-Silva et al., 2012). On the other hand, it seems that stress-related signals are not involved in diet-induced hypothalamic plasticity because familiar conditions, like reexposure to HFD, still produced upregulation of the plasticity marker PSA, whereas food novelty was not sufficient to induce this response.

Since hypothalamic plasticity appears to be a widely conserved process (Peinado et al., 2002; Pinto et al., 2004; Ebling and Barrett, 2008; Appelbaum et al., 2010; Baroncini et al., 2010), dietinduced hypothalamic plasticity could be present in humans as well. Indeed, haploinsufficiency of BDNF, the typical permissive factor of brain plasticity, is associated with childhood-onset obesity (Han et al., 2008). Furthermore, two recent genome-wide association studies of large human cohorts have reported a strong association between a high body-mass index and polymorphic loci whose neighboring genes are highly expressed in the brain and appear to be involved in neuronal development and/or activity (Thorleifsson et al., 2009; Willer et al., 2009). Thus, these studies highlight the crucial role that brain plasticity may play in regulating food intake and energy homeostasis in humans as well.

In conclusion, our findings bring new insights into the regulation of food intake. We show that the melanocortin system quickly adapts to the ingested food. Diet-induced rewiring of POMC neurons produces effects on energy intake. Inability to initiate diet-induced hypothalamic plasticity is obesogenic and could therefore be a new factor in the etiology of metabolic diseases.

\section{References}

Abizaid A, Liu ZW, Andrews ZB, Shanabrough M, Borok E, Elsworth JD, Roth RH, Sleeman MW, Picciotto MR, Tschöp MH, Gao XB, Horvath TL (2006) Ghrelin modulates the activity and synaptic input organization of midbrain dopamine neurons while promoting appetite. J Clin Invest 116:3229-3239.

Andrews ZB, Liu ZW, Wallingford N, Erion DM, Borok E, Friedman JM, Tschöp MH, Shanabrough M, Cline G, Shulman GI, Coppola A, Gao XB, Horvath TL, Diano S (2008) UCP2 mediates ghrelin's action on NPY/ AgRP neurons by lowering free radicals. Nature 454:846-851.

Appelbaum L, Wang G, Yokogawa T, Skariah GM, Smith SJ, Mourrain P, Mignot E (2010) Circadian and homeostatic regulation of structural synaptic plasticity in hypocretin neurons. Neuron 68:87-98.

Baroncini M, Jissendi P, Catteau-Jonard S, Dewailly D, Pruvo JP, Francke JP, Prevot V (2010) Sex steroid hormones-related structural plasticity in the human hypothalamus. Neuroimage 50:428-433.

Bermudez-Silva FJ, Cardinal P, Cota D (2012) The role of the endocannabi- noid system in the neuroendocrine regulation of energy balance. J Psychopharmacol 26:114-124.

Berthoud HR, Morrison C (2008) The brain, appetite, and obesity. Annu Rev Psychol 59:55-92.

Bramham CR, Wells DG (2007) Dendritic mRNA: transport, translation and function. Nat Rev Neurosci 8:776-789.

Butler AA, Marks DL, Fan W, Kuhn CM, Bartolome M, Cone RD (2001) Melanocortin-4 receptor is required for acute homeostatic responses to increased dietary fat. Nat Neurosci 4:605-611.

Cajigas IJ, Will T, Schuman EM (2010) Protein homeostasis and synaptic plasticity. EMBO J 29:2746-2752.

Chiu SL, Cline HT (2010) Insulin receptor signaling in the development of neuronal structure and function. Neural Dev 5:7.

Cone RD (2005) Anatomy and regulation of the central melanocortin system. Nat Neurosci 8:571-578.

Coppola A, Liu ZW, Andrews ZB, Paradis E, Roy MC, Friedman JM, Ricquier D, Richard D, Horvath TL, Gao XB, Diano S (2007) A central thermogenic-like mechanism in feeding regulation: an interplay between arcuate nucleus T3 and UCP2. Cell Metab 5:21-33.

Cowley MA, Smart JL, Rubinstein M, Cerdán MG, Diano S, Horvath TL, Cone RD, Low MJ (2001) Leptin activates anorexigenic POMC neurons through a neural network in the arcuate nucleus. Nature 411:480-484.

Crosby KM, Inoue W, Pittman QJ, Bains JS (2011) Endocannabinoids gate state-dependent plasticity of synaptic inhibition in feeding circuits. Neuron 71:529-541.

Diano S, Liu ZW, Jeong JK, Dietrich MO, Ruan HB, Kim E, Suyama S, Kelly K, Gyengesi E, Arbiser JL, Belsham DD, Sarruf DA, Schwartz MW, Bennett AM, Shanabrough M, Mobbs CV, Yang X, Gao XB, Horvath TL (2011) Peroxisome proliferation-associated control of reactive oxygen species sets melanocortin tone and feeding in diet-induced obesity. Nat Med 17:1121-1127.

Ebling FJ, Barrett P (2008) The regulation of seasonal changes in food intake and body weight. J Neuroendocrinol 20:827-833.

Eckhardt M, Bukalo O, Chazal G, Wang L, Goridis C, Schachner M, GerardySchahn R, Cremer H, Dityatev A (2000) Mice deficient in the polysialyltransferase ST8SiaIV/PST-1 allow discrimination of the roles of neural cell adhesion molecule protein and polysialic acid in neural development and synaptic plasticity. J Neurosci 20:5234-5244.

Enriori PJ, Evans AE, Sinnayah P, Jobst EE, Tonelli-Lemos L, Billes SK, Glavas MM, Grayson BE, Perello M, Nillni EA, Grove KL, Cowley MA (2007) Diet-induced obesity causes severe but reversible leptin resistance in arcuate melanocortin neurons. Cell Metab 5:181-194.

Gao Q, Mezei G, Nie Y, Rao Y, Choi CS, Bechmann I, Leranth C, ToranAllerand D, Priest CA, Roberts JL, Gao XB, Mobbs C, Shulman GI, Diano S, Horvath TL (2007) Anorectic estrogen mimics leptin's effect on the rewiring of melanocortin cells and Stat 3 signaling in obese animals. Nat Med 13:89-94.

Gyengesi E, Liu ZW, D’Agostino G, Gan G, Horvath TL, Gao XB, Diano S (2010) Corticosterone regulates synaptic input organization of POMC and NPY/AgRP neurons in adult mice. Endocrinology 151:5395-5402.

Han JC, Liu QR, Jones M, Levinn RL, Menzie CM, Jefferson-George KS, Adler-Wailes DC, Sanford EL, Lacbawan FL, Uhl GR, Rennert OM, Yanovski JA (2008) Brain-derived neurotrophic factor and obesity in the WAGR syndrome. N Engl J Med 359:918-927.

Horvath TL, Sarman B, García-Cáceres C, Enriori PJ, Sotonyi P, Shanabrough M, Borok E, Argente J, Chowen JA, Perez-Tilve D, Pfluger PT, Brönneke HS, Levin BE, Diano S, Cowley MA, Tschöp MH (2010) Synaptic input organization of the melanocortin system predicts dietinduced hypothalamic reactive gliosis and obesity. Proc Natl Acad Sci U S A 107:14875-14880.

Hübener M, Bonhoeffer T (2010) Searching for engrams. Neuron 67:363-371

Lafourcade M, Larrieu T, Mato S, Duffaud A, Sepers M, Matias I, De SmedtPeyrusse V, Labrousse VF, Bretillon L, Matute C, Rodríguez-Puertas R, Layé S, Manzoni OJ (2011) Nutritional omega-3 deficiency abolishes endocannabinoid-mediated neuronal functions. Nat Neurosci 14:345-350.

McEwen BS (2010) Stress, sex, and neural adaptation to a changing environment: mechanisms of neuronal remodeling. Ann N Y Acad Sci 1204 Suppl:E38-E59.

McNay DE, Briançon N, Kokoeva MV, Maratos-Flier E, Flier JS (2012) Re- 
modeling of the arcuate nucleus energy-balance circuit is inhibited in obese mice. J Clin Invest 122:142-152.

Mountjoy KG (2010) Functions for pro-opiomelanocortin-derived peptides in obesity and diabetes. Biochem J 428:305-324.

Oliet SH (2002) Functional consequences of morphological neuroglial changes in the magnocellular nuclei of the hypothalamus. J Neuroendocrinol 14:241-246.

Peinado JR, Castaño JP, Vázquez-Martínez R, Anouar Y, Tonon MC, Vaudry H, Gracia-Navarro F, Malagón MM (2002) Amphibian melanotrophs as a model to analyze the secretory plasticity of endocrine cells. Gen Comp Endocrinol 126:4-6.

Pillot B, Duraffourd C, Bégeot M, Joly A, Luquet S, Houberdon I, Naville D, Vigier M, Gautier-Stein A, Magnan C, Mithieux G (2011) Role of hypothalamic melanocortin system in adaptation of food intake to food protein increase in mice. PloS One 6:e19107.

Pinto S, Roseberry AG, Liu H, Diano S, Shanabrough M, Cai X, Friedman JM, Horvath TL (2004) Rapid rewiring of arcuate nucleus feeding circuits by leptin. Science 304:110-115.

Pocai A, Morgan K, Buettner C, Gutierrez-Juarez R, Obici S, Rossetti L (2005) Central leptin acutely reverses diet-induced hepatic insulin resistance. Diabetes 54:3182-3189.

Pocai A, Lam TK, Obici S, Gutierrez-Juarez R, Muse ED, Arduini A, Rossetti L (2006) Restoration of hypothalamic lipid sensing normalizes energy and glucose homeostasis in overfed rats. J Clin Invest 116:1081-1091.

Prevot V (2002) Glial-neuronal-endothelial interactions are involved in the control of GnRH secretion. J Neuroendocrinol 14:247-255.

Rutishauser U (2008) Polysialic acid in the plasticity of the developing and adult vertebrate nervous system. Nat Rev Neurosci 9:26-35.

Sternson SM, Shepherd GM, Friedman JM (2005) Topographic mapping of $\mathrm{VMH} \rightarrow$ arcuate nucleus microcircuits and their reorganization by fasting. Nat Neurosci 8:1356-1363.

Strader AD, Reizes O, Woods SC, Benoit SC, Seeley RJ (2004) Mice lacking the syndecan-3 gene are resistant to diet-induced obesity. J Clin Invest 114:1354-1360.

Theodosis DT, Rougon G, Poulain DA (1991) Retention of embryonic features by an adult neuronal system capable of plasticity: polysialylated neural cell adhesion molecule in the hypothalamo-neurohypophysial system. Proc Natl Acad Sci U S A 88:5494-5498.

Thorleifsson G, Walters GB, Gudbjartsson DF, Steinthorsdottir V, Sulem P, Helgadottir A, Styrkarsdottir U, Gretarsdottir S, Thorlacius S, Jonsdottir I, Jonsdottir T, Olafsdottir EJ, Olafsdottir GH, Jonsson T, Jonsson F, Borch-Johnsen K, Hansen T, Andersen G, Jorgensen T, Lauritzen T, et al. (2009) Genome-wide association yields new sequence variants at seven loci that associate with measures of obesity. Nat Genet 41:18-24.

Vimr ER, McCoy RD, Vollger HF, Wilkison NC, Troy FA (1984) Use of prokaryotic-derived probes to identify poly(sialic acid) in neonatal neuronal membranes. Proc Natl Acad Sci U S A 81:1971-1975.

Wang J, Obici S, Morgan K, Barzilai N, Feng Z, Rossetti L (2001) Overfeeding rapidly induces leptin and insulin resistance. Diabetes 50:2786-2791.

Willer CJ, Speliotes EK, Loos RJ, Li S, Lindgren CM, Heid IM, Berndt SI, Elliott AL, Jackson AU, Lamina C, Lettre G, Lim N, Lyon HN, McCarroll SA, Papadakis K, Qi L, Randall JC, Roccasecca RM, Sanna S, Scheet P, et al. (2009) Six new loci associated with body mass index highlight a neuronal influence on body weight regulation. Nat Genet 41:25-34

Yang Y, Atasoy D, Su HH, Sternson SM (2011) Hunger states switch a flipflop memory circuit via a synaptic AMPK-dependent positive feedback loop. Cell 146:992-1003.

Zhang G, Bai H, Zhang H, Dean C, Wu Q, Li J, Guariglia S, Meng Q, Cai D (2011) Neuropeptide exocytosis involving synaptotagmin-4 and oxytocin in hypothalamic programming of body weight and energy balance. Neuron 69:523-535.

Ziotopoulou M, Mantzoros CS, Hileman SM, Flier JS (2000) Differential expression of hypothalamic neuropeptides in the early phase of dietinduced obesity in mice. Am J Physiol Endocrinol Metab 279:E838-E845. 